Filosofia 


\section{Adorno e Kierkegaard}

SERGIO PAULO ROUANET ${ }^{I}$

$\mathrm{U}$ MA VELHA tradição acadêmica nos obriga a buscar um ponto de contato com a chamada realidade brasileira sempre que nos dispomos a falar sobre um autor estrangeiro. Essa tarefa é facilitada quando o autor se chama Stefan Zweig, que escreveu sobre o Brasil e morreu em Petrópolis. Ou Thomas Mann, filho de uma brasileirinha de Paraty. Ou Bernanos, que passou boa parte da guerra refugiado no Brasil. "Abrasileiramos" nosso autor, que se torna um pouco nosso compatriota. Criamos com isso uma certa simpatia em nosso público, utilizando um artifício de sedução que a antiga retórica chamava captatio benevolentiae.

Mas parece difícil aplicar essa técnica aos dois pensadores que figuram no título desta palestra: Adorno (1903-1969) e Kierkegaard (1813-1855).

Sem dúvida, podemos procurar um ponto de contato na mera influência desses filósofos no Brasil. A doutrina de Kierkegaard chegou ao Brasil na vaga existencialista que também trouxe consigo Heidegger e Sartre, e foi muitíssimo lida pela juventude brasileira de pós-guerra. Adorno foi um autor cult, cujo prestigio vinha em grande parte de sua obscuridade. Ele foi lido com avidez pelos jovens que frequentavam a praia de Ipanema nos meses que antecederam o golpe militar de 1964. Precisamos algo mais para demonstrar o lado "brasileiro" dos dois filósofos?

Precisamos, sim: falta a dimensão pessoal.

A ligação pessoal de Adorno com o Brasil é indireta, mas para mim de grande significado afetivo. Ele nunca foi professor na USP, como quase aconteceu com seu amigo Walter Benjamin, mas foi professor em Frankfurt de uma pessoa que se encontra hoje nesta sala, a quem devo tudo o que sei sobre a teoria crítica. Passadas quatro décadas, Barbara Freitag continua interessada nesse tema, sobre o qual organizou recentemente, para a Tempo Brasileiro, uma coletânea de ensaios, intitulada Adorno 100 anos.

No que se refere a Kierkegaard, a dimensão pessoal é fornecida pelo fato de que o filósofo era compatriota e parente pelo lado materno de Peter Wilhelm Lund, o mesmo que fez escavações paleontológicas em Minas Gerais e descobriu o "homem da Lagoa Santa". Os dois se escreviam, um na Dinamarca e o outro no Brasil.

Quem tinha um interesse enorme por toda essa temática era outro dinamarquês, o romancista Henrik Stangerup. Ele esteve no Brasil, onde trabalhou num filme intitulado Erasmus Montana, baseado numa peça de Holberg, comediógrafo dinamarquês muito citado por Kierkegaard. No Brasil, Stangerup co- 
lheu materiais para escrever um dos seus maiores sucessos, $O$ caminho de Lagoa Santa, publicado em 1981 e já traduzido em português. O romance, quase todo passado no Brasil, menciona com grande frequência o nome de Kierkegaard.

Outra curiosa convergência com o Brasil foi produzida quando Stangerup e o historiador britânico Poole resolveram publicar uma coletânea dos textos literários de Kierkegaard. Segundo informa Poole, os dois colaboradores passavam horas combinando os detalhes do seu trabalho, em intermináveis caminhadas por uma rua de Paris, a rue de Bassano, onde na época residia Stangerup. Poole não diz o número, mas esclarece que durante essas caminhadas, passavam pela casa que fora o Quartel General da Gestapo, durante a ocupação. Acontece que a casa ao lado era o número 40, um prédio sem nenhum interesse arquitetônico especial. O pequeno detalhe era que nesse local ficava o palacete de propriedade de Eufrásia Teixeira Leite, o grande amor da vida de Joaquim Nabuco. Coincidências, cruzamentos, correspondências, no sentido de Baudelaire e de Breton: encruzilhadas noturnas ligando o passado ao presente, o amor à tortura, a barbárie da escravidão à barbárie do nazismo, Paris ao Rio, numa trajetória em que não se sabe mais qual era a cidade tropical e qual a que Walter Benjamin chamou "a capital do século XIX". Mas como para o flâneur toda cidade é sempre exótica, sobretudo quando se trata de sua cidade natal, e como o número 40 da rue de Bassano tem um muro revestido de hera, exatamente como a casa de Vassouras onde Eufrásia passou a infầncia, podemos conjeturar que para os dois flâneurs, que bem entendido nunca tinham ouvido falar nem em Nabuco nem em sua noiva, a cidade misteriosa era Paris, o longe trazido para perto, como na época das exposições universais, em que os citadinos podiam observar em Paris, transformada em cidade exótica, neves tibetanas e florestas amazônicas.

Falar da relação entre dois pensadores, um dos quais produziu uma interpretação do outro, significa fazer duas coisas. Por um lado, o expositor precisa examinar essa interpretação, desvendando os pressupostos do intérprete, seus $a$ prioris culturais, seus condicionamentos ideológicos. Por outro lado, ele precisa investigar em que medida o próprio intérprete foi influenciado em sua obra posterior pelas ideias que ele descobriu no interpretado.

É o caso exemplar da relação entre Adorno e Kierkegaard. Adorno interpretou Kierkegaard segundo uma óptica marxista muito particular, que tentava afastar-se do materialismo histórico ortodoxo, nas linhas do que veio a ser conhecido como o marxismo ocidental e mais especificamente, a Escola de Frankfurt. A tarefa, no caso, é examinar a validade dessa análise. E depois impõe-se fazer o movimento inverso, procurando na obra posterior de Adorno os ecos do pensamento de Kierkegaard. No primeiro caso, Kierkegaard é objeto de interpretação, e no segundo, é fonte para a compreensão do pensamento de Adorno e da teoria crítica em geral.

A pergunta, no primeiro caso, é simples: que avaliação podemos fazer hoje da interpretação de Kierkegaard feita por Adorno? 
Essa interpretação está contida essencialmente na tese de pós-doutorado, ou de habilitation, na terminologia alemã, que o jovem Theodor Wiesengrund Adorno apresentou a seu orientador, Paul Tillich, em 1931. A tese foi publicada em livro dois anos depois, sob o título Kierkegaard: a construção do estético. As edições posteriores contêm dois apêndices, um sobre "A doutrina do amor em Kierkegaard", na edição de 1962, e outro intitulado "Kierkegaard mais uma vez", na edição de 1966.

Quando Adorno defendeu sua tese, em 1931, Kierkegaard já não era o pensador relativamente marginal que poucos levavam a sério na Dinamarca. Pouco demais de sua morte, já era respeitado como jornalista, filósofo e teólogo. Sua polêmica contra a Igreja luterana dinamarquesa, que para ele era o reduto de uma ortodoxia burocrática e obscurantista, suscitou evidentemente reações indignadas, mas ninguém contestava mais a força e a originalidade do seu pensamento. As primeiras traduções contribuíram muito para a difusão de suas ideias. O mundo alemão já as conhecia pelo menos desde 1905, quando Hermann Gottsche publicou os diários de Kierkegaard. Suas obras principais tinham sido traduzidas por Christoph Schrempf a partir de 1909. Os teólogos protestantes (entre os quais Karl Barth e Rudolf Bultman) agrupados em torno da revista Zwischen den Zeiten, lançada em 1922, estudaram a fundo a teoria de Kierkegaard, o mesmo acontecendo com os adeptos da chamada teologia do diálogo, entre os quais Martin Buber e Franz Rosenzweig,. Em Sein und Zeit, publicado, em 1927, Heidegger utiliza explicitamente certas categorias de Kierkegaard.

Isso não significa que a filosofia do pensador dinamarquês tivesse se tornado aceitável para todos os marxistas. Mesmo os mais abertos, como o jovem Lukács de Historia e consciência de classe, não tinham grande simpatia por um filósofo que parecia menosprezar o social, dizia que "o verdadeiro estava unicamente na interioridade", independentemente do mundo exterior, e tomara partido, nas revoluções liberais de 1848 , pela causa do poder e da repressão.

Esse preconceito afetava os próprios integrantes do Instituto de Pesquisa Social, núcleo básico do que mais tarde seria conhecido como a Escola de Frankfurt. Seu diretor, Horkheimer, elogiou a tese de Adorno, mas escreveu que as ideias de Kierkegaard eram profundamente alheias ao seu modo de pensar.

Adorno partilhava muitas dessas objeções, mas no quadro de uma "crítica "salvadora", como a praticada por Walter Benjamin em sua análise do drama barroco, uma crítica que não destrói a obra, mas busca redimi-la, trazendo à luz seu conteúdo de verdade.

O procedimento de Adorno consiste, assim, não em sociologizar Kierkegaard, mas em desprender o conteúdo social desde sempre alojado na essência da obra. O antissocial em Kierkegaard faz parte do próprio movimento do social. É o produto de uma exterioridade reificada, produzida por relações humanas opacas, que não se deixam devassar pelo sujeito, e por isso são voltadas para dentro. Seu anti-hegelianismo não se dirige contra o pensamento dialético 
em si, mas contra a legitimidade de uma dialética pacificadora, com a síntese esperando, no fim do caminho, para absorver todos os contrários, eliminando a estrutura paradoxal da existência humana. Por isso, ele não pode ser classificado entre os hegelianos de esquerda, como Feurbach e Marx, que se limitavam a "repor a dialética sobre seus pés", pois sua dialética é uma dialética sem síntese, uma dialética negativa, que nenhum verdadeiro hegeliano, de direita ou de esquerda, poderia aceitar.

Mas como explicar, sociologicamente, o conceito-chave de Kierkegaard, a interioridade? Seu correlato no mundo objetivo é o interior burguês. A obra de Kierkegaard está cheia de pequenas vinhetas descrevendo salões da média e alta burguesia: ornatos, pêndulas, cortinas, quadros e sobretudo espelhos. É um mundo fechado, que não precisa de ventilação. Pode-se fazer tudo no interior, até mesmo flanar. É o que fazia o pequeno Kierkegaard, quando o pai o levava pela mão, para passear. Eram passeios esplêndidos, porque o menino tinha o privilégio, só concedido a príncipes de sangue real, de escolher o lugar de destino. Ora os dois viajavam para castelos, ora para praias, ora para montanhas. Passeios intermináveis, porque se davam inteiramente na imaginação, como as viagens de Xavier de Maistre, que não ultrapassavam os limites de um quarto. O pai podia ir para onde quisesse, porque os pais podem tudo, como sabe qualquer criança, Enquanto caminhavam, o pai explicava tudo o que viam, conversava com todos os transeuntes, e as frutas expostas nas vitrinas eram mais apetitosas que nunca. Mais tarde, Kierkegaard flanava num espaço mais amplo, mas sempre fechado, grande salão circunscrito pelas muralhas da velha Copenhagen, e nessas ocasiões deve ter pensado nas viagens que no mesmo momento Peter Lund fazia no "grande sertão" de Minas Gerais.

Mas quem habita o interior? O rentier. Alguém segregado do processo produtivo, como o próprio Kierkegaard, que não tinha nenhum trabalho remunerado, e vivia do rendimento de ações herdadas do pai, que tinham se desvalorizado no final da vida do filósofo. O rentier conhece o tempo, porque esse é dos elementos da interioridade, mas não conhece a história. Ele vê a história acontecendo na rua, pela janela do seu salão, mas é sempre a história como Schein, como aparência, ilusão - a única maneira pela qual a história pode ser vivida pelo particular no interior burguês. Ela é um ornamento na interioridade vazia da consciência, uma objektlose Innerlichkeit. Mas esse Schein pode ser perverso, demoníaco, provocando mortes e perdas materiais, como em 1848, ano em que Kierkegaard teve grandes prejuízos financeiros.

Além de exorcizar a história, o filósofo-rentier exorciza também a natureza. Ele condena o prazer, a felicidade profana, a livre sexualidade. Foi perseguido toda a vida pela culpa, por ter visitado um bordel, o que o levou a romper o noivado com Regina Olsen. Culpa duas vezes grave, porque era uma culpa hereditária, como a procedente do pecado original. Pois o pai, que ele idolatrava, também fora um pecador, não somente por ter mantido um relacionamento 
extraconjugal, como por ter amaldiçoado Deus, quando criança. O pai estava convencido de que Deus se vingaria mais cedo ou mais tarde, o que pareceu confirmar-se, pois entre 1819 e 1834 morreram sucessivamente a mãe de Soren, três irmãs mais velhas, e dois dos seus irmãos. O velho Kierkegaard se julgava condenado a sobreviver a todos os seus filhos, que não ultrapassariam nunca a idade de Cristo, 33 anos. Ou seja, por culpa dele, seus filhos seriam sacrificados. A profecia não se verificou no caso de Soren, que morreu com 42 anos, mas a ideia do sacrifício permaneceu uma das constantes de sua filosofia. Ele se referiu várias vezes ao sacrifício de Ifigênia por Agammenon, e dedicou todo um livro à exegese da narrativa bíblica sobre a ordem divina dada a Abraão de sacrificar seu filho Isaac.

Mas para Adorno, a própria radicalidade da filosofia de Kierkegaard, que recusa qualquer conivência com o existente, tanto em suas estruturas eclesiásticas como seculares, permite entrever os contornos de uma intuição justa sobre a história e a natureza. É uma “crítica salvadora”, na melhor tradição benjaminiana, que nisso aliás é autenticamente marxista, como demonstra o entusiasmo de Marx pela lucidez sociológica de Balzac, que apesar de suas posições políticas legitimistas teria devassado melhor que qualquer revolucionário os mecanismos de poder numa sociedade baseada no capital.

Sem dúvida, para Kierkegaard, a salvação verdadeira é de natureza espiritual e só pode dar-se pela religião. A salvação não é deste mundo. Mas além dessa redenção mítica, há na filosofia de Kierkegaard, segundo Adorno, um espaço de liberdade que permite pensar uma salvação terrena, que ultrapassa as fronteiras da mera interioridade. Esse espaço estaria localizado na esfera estética, ponto de partida do itinerário do espírito em direção aos outros dois estágios: o ético e o religioso. O estágio ético é a relação do homem com o dever, e o religioso, sua relação com Deus. Já o estágio estético é a relação do homem com sua sensibilidade. É o reino da espontaneidade, da dispersão, do descontínuo. É o não mediatizado, o ócio, o lugar de uma entrega não reflexiva à mera existência. É a esfera da arte, do amor, da sedução. Como bom pietista, Kierkegaard desaprova moralmente a atitude estética, que para ele é irresponsável, e impede o espírito de dar o "salto" da fé, ingressando no estágio religioso. Ao mesmo tempo, não nos esqueçamos de que o próprio Kierkegaard foi um “esteta”, tanto no sentido convencional do interesse pelo teatro, pela literatura e pela música (o Don Giovanni, de Mozart, era para ele a maior obra de arte de todos os tempos) como no sentido mais idiossincrático de libertinagem. É evidente que o Kierkegaard religioso tem um fraco pelo Kierkegaard esteta. "Não há nada mais ridículo", diz ele, "que uma atitude de profundidade e de seriedade estúpida onde um humor brincalhão e categorias estéticas seriam mais apropriadas."

Adorno prossegue sua crítica salvadora citando uma passagem em que um “ético" zomba de um “esteta”: "Se tudo o que V. tem a dizer é que não suporta mais tudo isso, V. deveria procurar um mundo melhor”. E Adorno conclui: 
Søren Aabye Kierkegaard

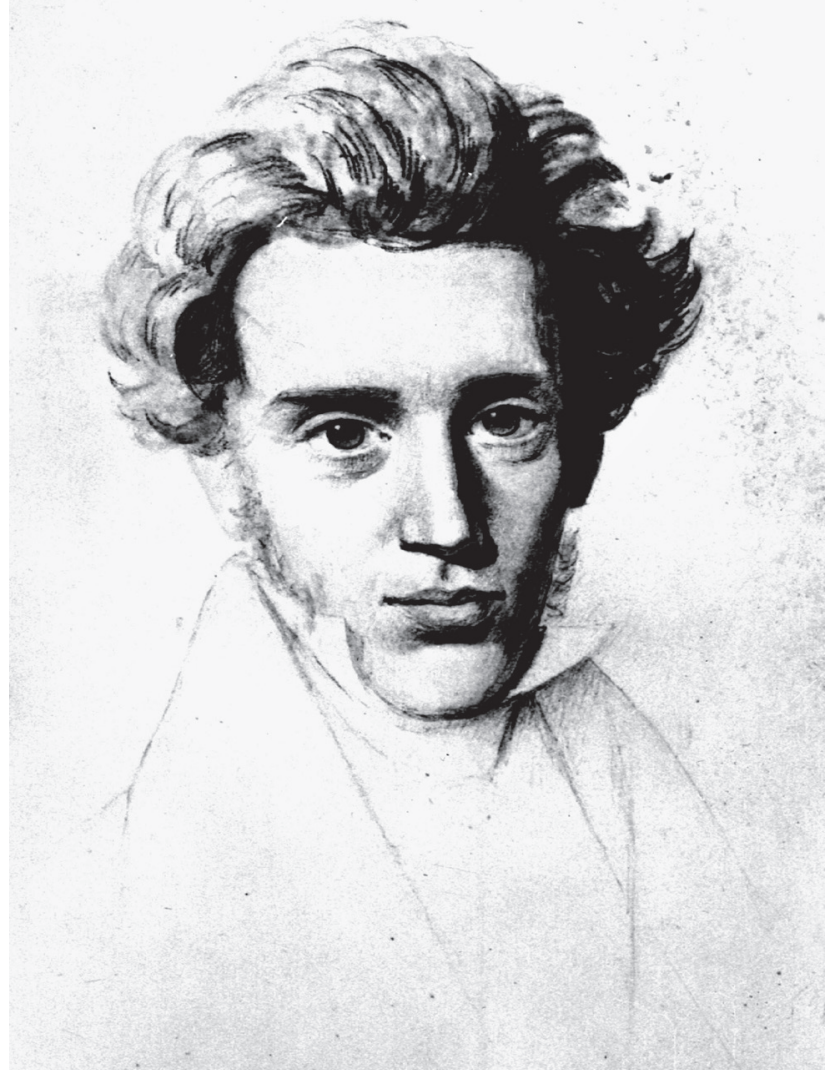

Aquilo que de modo tão zombeteiro o "ético" censura no "esteta" é contudo o que este possui de melhor... como célula de um materialismo que procura "um mundo melhor", não para esquecer, sonhando, o mundo existente, mas para mudá-lo, graças à força de uma imagem ...cujos contornos se realizam em cada momento dialético de modo corporal e unívoco. A quintessência dessas imagens é a esfera estética de Kierkegaard.

Qual o valor, atualmente, da interpretação de Kierkegaard realizada por Adorno? A meu ver sua principal fragilidade, que é também, literária e filosoficamente, sua maior virtude, é o método de atribuir a Kierkegaard intenções políticas inconscientes, fazendo desse hiperconservador um marxista avant la lettre. Dito isso, a análise de Adorno é sem dúvida a tentativa mais bem-sucedida de compreender Kierkegaard segundo as categorias de um marxismo não reducionista. Em nenhum momento Adorno diz que a filosofia de Kierkegaard é uma superestrutura ideológica, o que reduziria seu pensamento a um simples epifenômeno das condições materiais. Ele se limita a apontar para uma relação de analogia ou de isomorfismo, portanto sem caráter causal, entre certos aspectos sociais e certas manifestações da cultura, como a que ele estabelece entre a filosofia da interioridade e o interior burguês.

Outra crítica, esta sem caráter político, é a de que Adorno teria tratado as obras de Kierkegaard como se todas representassem desdobramentos coerentes 


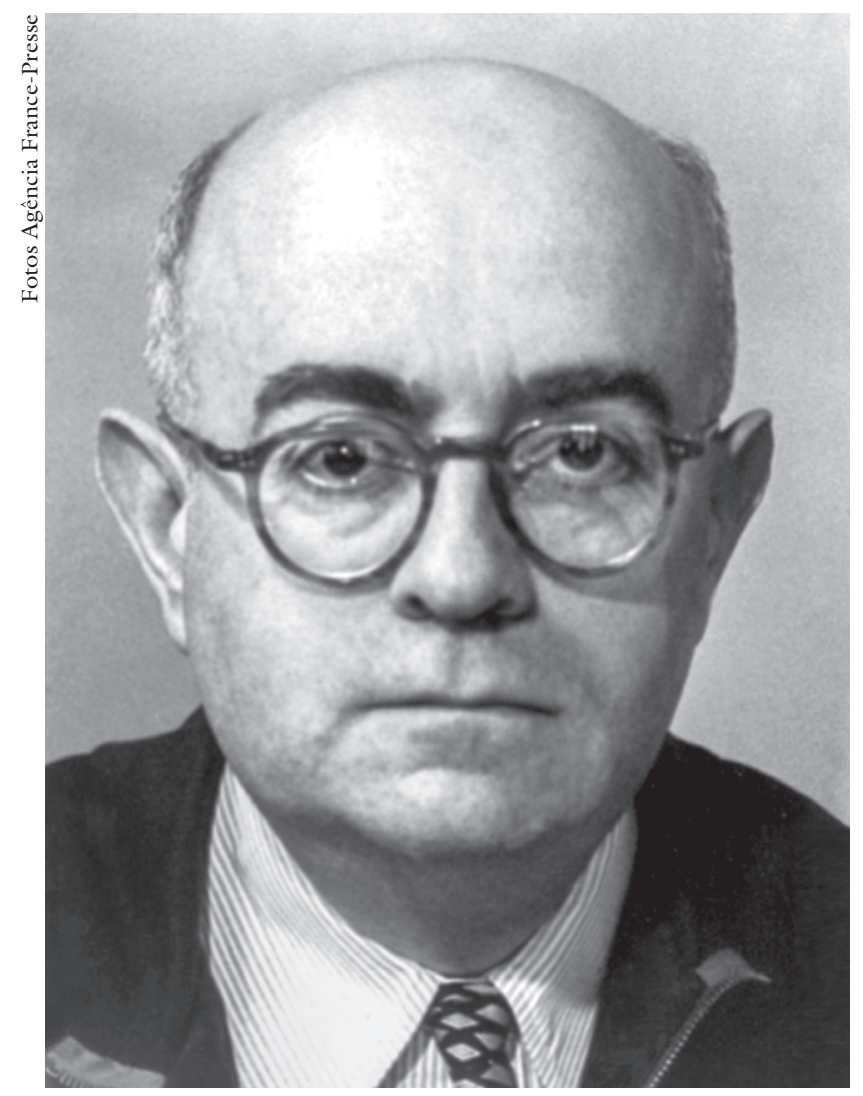

Theodor Ludwig W Adorno

de um pensamento único, deixando de lado uma das principais características formais de sua técnica de apresentação, a ficção de que cada uma seria escrita por um autor diferente. Assim, "Ou-ou" é assinado por Victor Eremita; "Temor e tremor", por Johannes de Silentio; "O conceito de Angustia", por Vigilius Haufniensus; e "Migalhas filosóficas", por Johannes Climacus. Segundo os críticos, ignorar esse artifício da autoria múltipla falsifica Kierkegaard, que pretende, justamente, dissociar-se da unidade espúria do sistema, mostrando-se a seus leitores em toda a riqueza de suas contradições.

Conversando com Cleonice Berardinelli sobre a óbvia semelhança que existe nesse ponto entre Kierkegaard e Fernando Pessoa, dei-me conta da importância crítica de distinguir entre pseudônimos e heterônimos Os primeiros são nomes falsos, e os segundos são literalmente "nomes de outros"; Kierkegaard trabalha com pseudônimos; Pessoa, com heterônimos. Neste, parece haver realmente uma Spaltung, uma cisão do Eu, sua divisão em vários “outros”, como Álvaro de Campos, Ricardo Reis, Alberto Caeiro e Bernardo Soares, e na qual o próprio Fernando Pessoa parece ser apenas mais um desses outros, sem nenhum privilégio ontológico com relação às demais figuras da heteronímia. Já Kierkegaard recorre à pseudonímia, usando nomes supostos, como o agente secreto que às vezes ele dizia ser, sem se expor a nenhum processo de desintegração do $\mathrm{Eu}$, porque tem plena consciência de estar utilizando uma simples ficção metodológica, destinada 
a ilustrar o caráter múltiplo e paradoxal da existência. Se isso é verdade, não parece que Adorno tenha cometido um erro de interpretação muito grave atribuindo a um só e mesmo filósofo - Kierkegaard - obras assinadas por autores diferentes.

Falta agora dar um segundo passo: não mais examinar a interpretação que Adorno faz de Kierkegaard, mas de examinar a contribuição dada por Kierkegaard ao pensamento de Adorno, e ao de seus companheiros do Institut für Sozialforschung.

Essa contribuição só se tornou frutífera depois que a tese de Adorno "desencantou" a filosofia de Kierkegaard, fazendo por ela o que Marx fizera pelo idealismo de Hegel. Assim, Adorno teria rompido o invólucro místico de Kierkegaard, liberando seu "núcleo racional". Feito isso, as ideias do pensador dinamarquês constituíram algumas das fontes mais importantes para a formação e desenvolvimento da teoria crítica.

Entre essas ideias, a mais decisiva é a importância da individualidade, crescentemente sabotada pelos dois totalitarismos rivais que estavam esmagando o sujeito - o nazismo e o stalinismo - aos quais se acrescia a despersonalização advinda da sociedade de massas, nos próprios países democráticos. Contra essas tendências, a "interioridade" kierkegaardiana, devidamente laicizada, parecia oferecer um santuário extraterritorial. Mais que um refúgio, a interioridade podia ser o lugar de uma resistência: a innere Emigration, a emigração interna, a recusa radical e absoluta do sujeito de mitmachen, de colaborar com o inimigo externo. Foi a luta travada pelo pintor Emil Nolde, a dar crédito ao romance Deutschstunde, de Siegfried Lenz.

Nessa luta pela livre subjetividade, Adorno atribuía à arte um papel decisivo. Era uma "promessa de felicidade", como ele gostava de dizer, citando Stendhal. Reconhecemos nessa prioridade o privilégio que, apesar de todo o seu rigorismo moral, Kierkegaard reconhecia à esfera estética.

A angústia com a desindividualização é um leitmotiv do pensamento de Adorno. Ele recorda, nostalgicamente, a época em que o processo de socialização se fazia pelo jogo das instâncias psíquicas, no próprio individuo, num trajeto que podia levar à formação de personalidades autônomas. Hoje, o processo de gestão das consciências se tornou demasiadamente importante para ser deixado à contingência do psiquismo individual. A administração do consenso é feita diretamente pelo todo social.

Numa troca de correspondência com Walter Benjamin, Adorno o censura por ter defendido a existência de sonhos coletivos. Para Adorno, a ideia do sonho coletivo é uma aberração junguiana. É uma noção mítica, porque apesar de todas as interações entre a realidade exterior e a cena onírica, quem sonha é sempre o indivíduo. Não é uma apologia do individualismo, acrescenta ele, mas o individuo burguês deve ser aufgehoben, transcendido dialeticamente, e não wegmythisiert, dissolvido no mito.

A salvação do particular é uma ideia fixa em Adorno, quase tão obsessiva 
quanto em Kierkegaard. Para este, é uma salvação no sentido religioso, já que a relação com Deus, com a ira de Deus, com o tribunal de Deus, é sempre uma relação com o indivíduo. Para Adorno, salvar o particular significa defendê-lo das investidas do sistema. Nos dois casos, é uma atitude de rebeldia contra Hegel. Kierkegaard quer salvar o particular rompendo com a filosofia especulativa, que afasta do concreto. Adorno quer salvá-lo rompendo com a totalidade, categoria hegeliana muito cara a Lukács, mas que não por acaso tem a mesma raiz que totalitarismo. Por isso, Adorno corrige a frase de Hegel: “das Ganze ist das Wahre”, "o todo é o verdadeiro", para "das Ganze ist das Unwahre", "o todo é o falso".

Gostaria de encerrar esta palestra resumindo um texto intitulado "A idade presente". Nossa época, diz o autor, é caracterizada pelo nivelamento. Uma época apaixonada destrói e derruba tudo em nome da ação. Uma era desapaixonada nivela tudo. É a nossa época. A revolução é ruidosa como um vulcão em erupção. O nivelamento é silencioso, matemático, é um silêncio mortal em que se podem ouvir as batidas do nosso coração. $\mathrm{O}$ nivelamento não tem líderes, porque o líder se destacaria e escaparia ao nivelamento. O nivelamento é a vitória da abstração sobre o indivíduo, e nisso desempenha o papel do destino, na Antiguidade. O nivelamento busca a igualdade a todo preço, ao contrário do mundo antigo, em que o homem buscava sobressair pela virtude, pela areté. $\mathrm{O}$ indivíduo que nivela é ele mesmo engolfado pelo nivelamento, e mesmo quando acha saber o que está fazendo, as pessoas que constituem a massa não o sabem. Assim como o entusiasmo coletivo produz um excedente que não vem do indivíduo, há também um excedente no caso do processo de nivelamento. Um demônio é invocado, sobre quem nenhum indivíduo tem qualquer poder, e embora o indivíduo que nivela possa com isso ter um prazer momentâneo, ele está ao mesmo tempo assinando sua sentença de morte. O entusiasmo pode terminar na catástrofe; o nivelamento é a catástrofe - a destruição do indivíduo. O nivelamento não se limita a uma só nação: ele é global. Mas para que se dê o nivelamento, é preciso produzir um fantasma, uma abstração monstruosa, uma miragem: é o público. Maiorias ou minorias são compostas de pessoas concretas, enquanto o público é uma abstração. E quem cria o público? O jornal, o grande indutor de nivelamento.

Essas palavras constituem a síntese mais completa da teoria de Adorno sobre o nivelamento extremo (Marcuse falaria em unidimensionalização) que caracteriza a moderna sociedade de massas. Não falta nada, nem a referência à psicologia coletiva de Freud, que descreve o desaparecimento do indivíduo na massa. Há até uma pequena alusão profética ao nivelamento provocado pela globalização. E para não decepcionar os que não gostam da rede Globo, não está ausente nem mesmo uma crítica à imprensa (hoje falaríamos em mídia) como inventora do público e veículo do nivelamento. Mas em que obra de Adorno está mesmo essa passagem? Em nenhuma, porque ela não é de Adorno, e sim de Kierkegaard, nascido 90 anos antes de Adorno. 
RESUMO - Falar da relação entre dois pensadores, um dos quais produziu uma interpretação do outro, significa fazer duas coisas. Por um lado, o expositor precisa examinar essa interpretação, desvendando os pressupostos do intérprete, seus a prioris culturais, seus condicionamentos ideológicos. Por outro, ele precisa investigar em que medida o próprio intérprete foi influenciado em sua obra posterior pelas ideias que ele descobriu no interpretado. É o caso exemplar de Adorno e Kierkegaard. Adorno interpretou Kierkegaard segundo uma óptica marxista muito particular. A tarefa, no caso, é examinar a validade dessa análise. E depois impõe-se fazer o movimento inverso, procurando na obra de Adorno os ecos do pensamento de Kierkegaard. No primeiro caso, Kierkegaard é objeto de interpretação, e no segundo, é fonte para a interpretação da teoria crítica em geral. O autor tentou examinar as duas vertentes dessa dialética.

PALAVRAS-CHAVE: Filosofia, Teoria crítica, Adorno, Kierkegaard.

ABSTRACT - To speak of the relationship between two thinkers, one of whom produced an interpretation of the other, means doing two things. On one hand, we must examine this interpretation, exposing the assumptions of the interpreter, his cultural a priories, his ideological conditionings. On the other, we must investigate to what extent the interpreter himself was influenced, in his later works, by the ideas he uncovered in the interpreted. This is the exemplary case of Adorno and Kierkegaard. Adorno interpreted Kierkegaard according to a very particular Marxist viewpoint. Our task here is to examine the validity of such analysis. The reverse movement is then required, i.e., to seek in Adorno's works echoes of Kierkegaard's thinking. In the first case, Kierkegaard is the object of the interpretation; in the second, he is the source for a general interpretation of critical theory. We have tried to examine both aspects of this dialectics.

KEYWORDS: Philosophy, Critical theory, Adorno, Kierkegaard.

Sergio Paulo Ronanet nasceu no Rio de Janeiro, em 23 de fevereiro de 1934. Formou-se em Direito pela PUC do Rio de Janeiro. Fez cursos de pós-graduação em Economia (George Washington University), Ciência Política (Georgetown University) e Filosofia (New School for Social Research). Doutorou-se em Ciência Política pela USP. Diplomata de carreira, formado pelo Instituto Rio Branco. Entre outros postos, foi cônsul-geral em Zurique e em Berlim, e embaixador em Copenhague e Praga. Quando Secretário Nacional de Cultura, elaborou o projeto da lei de incentivo à cultura que leva seu nome. Professor na Universidade de Brasília. Ministrou curso em 2004 na Universidade de Oxford. Atualmente está coordenando a publicação da correspondência completa, ativa e passiva, de Machado de Assis. @ - bfreitag@uol.com.br

Exposição feita pelo autor no Ciclo de Conferências "Existência e alternativas: um olhar sobre Kierkegaard", promovido pela Academia Brasileira de Letras (ABL), no dia 12 de março de 2013, e publicada originalmente na Revista Brasileira, Fase VIII, abril-maio-junho 2013, Ano II, n. 75.

Recebido em 25.8.2013 e aceito em 10.9.2013.

I Academia Brasileira de Letras, Academia Brasileira de Filosofia, Instituto Histórico e Geográfico, Pen Clube. Rio de Janeiro/RJ, Brazil. 